\title{
O FENÔMENO DA SHIPPAGEM NA NOMEAÇÃO DE CASAIS: UM NOVO EMPREGO DO CRUZAMENTO VOCABULAR
}

\author{
Carlos Alexandre GONÇALVES ${ }^{1}$ \\ Vitória Benfica da SILVA²
}

\section{DOI: http://dx.doi.org/10.21165/gel.v18i3.3097}

Resumo: Neste artigo, descrevemos o fenômeno da shippagem (prática que consiste em nomear relações afetivas de personagens, casais ou amigos), utilizando, na representação dos dados, os instrumentos da Morfologia Prosódica (MCCARTHY, 1986). Tomamos por base contribuições existentes sobre o cruzamento vocabular em português (BASILIO, 2005; ANDRADE, 2013), a fim de verificar se a tipologia proposta para nomes comuns também se aplica a antropônimos shippados: (a) interposição ou entranhamento lexical; (b) combinação truncada e (c) reanálise ou substituição sublexical. Nosso corpus é constituído de 212 dados. Com exceção de 10 dados coletados de fala espontânea, todos os demais foram retirados da internet. A maioria dos ships coletados remete a programas de televisão ou a plataformas on-line de filmes, séries (como as da Netflix) e novelas. As principais fontes são os sites que falam sobre personagens e atores dessas narrativas, como revistas, jornais, fanfics, blogs diversos, além das redes sociais Twitter, Facebook e Instagram. Nesta descrição, pretendemos mostrar que nem sempre são muito claras as fronteiras entre os chamados processos não concatenativos, uma vez que ships parecem estar a meio caminho entre o cruzamento, de um lado, e a siglagem e a hipocorização de nomes compostos, de outro.

Palavras-chave: Morfologia. Formação de palavras. Cruzamento Vocabular. Shippagem.

\footnotetext{
1 Universidade Federal do Rio de Janeiro (UFRJ), Rio de Janeiro, Rio de Janeiro, Brasil; carlexandre@bol.com.br; https://orcid.org/0000-0003-3672-3852

2 Universidade Federal do Rio de Janeiro (UFRJ), Rio de Janeiro, Rio de Janeiro, Brasil; vitoriabds@gmail.com; https://orcid.org/0000-0002-3158-2985
} 
- | O fenômeno da shippagem na nomeação de casais: um novo emprego do cruzamento vocabular

\title{
THE PHENOMENON OF SHIPPING IN THE APPOINTMENT OF COUPLES: A NEW EMPLOY OF LEXICAL BLENDING
}

\begin{abstract}
In this paper, we analyze the phenomenon of shipping (a recent practice that consists of naming affective relationships of characters, couples or friends) in the light of the Prosodic Morphology (MCCARTHY, 1986) instruments of representations. We based in the existing descriptions about the lexical blending in Brazilian Portuguese (BASILIO, 2005; ANDRADE, 2013), in order to verify if the typology proposed for common names also applies to anthroponyms shipped: (a) lexical interposition; (b) truncated combination terminology) and (c) reanalysis or sublexical replacement. Our corpus consists of 212 data. With the exception of 10 data collected from spontaneous speech, all the rest were removed from the internet. Most of the ships collected refer to television programs or online platforms' for films, series (such as Netflix) and soap operas. The main sources are the sites that talk about characters and actors in these narratives, such as magazines, newspapers, fanfics, various blogs, in addition to the social networks Twitter, Facebook and Instagram. In this description, we intend to show that the boundaries between the so-called non-concatenative processes are not always very clear, since ships seem to be halfway between the blend, on the one hand, and the initialism and hypocorization of compound names, on the other.
\end{abstract}

Keywords: Morphology. Word formation. Lexical Blending. Shipping.

\section{Introdução}

Nesteartigo, analisamos uma prática bastante usual na criação de nomes: ashippagem, fenômeno que consiste em batizar uma relação afetiva por meio da combinação de dois antropônimos, a exemplo de "Neymarquezine", mescla do prenome do famoso jogador brasileiro de futebol, Neymar, com o sobrenome da atriz global Bruna Marquezine. O trabalho é pré-teórico e do tipo descritivo/analítico; utiliza-se da Morfologia Prosódica (McCARTHY, 1986; PIÑEROS, 2002) apenas para representar a estrutura morfofonológica dos produtos e para abordar as categorias mais baixas da hierarquia prosódica: sílabas e pés métricos.

Como ponto de partida para a investigação, pretendemos mostrar que o fenômeno é frequentemente utilizado nas mídias sociais e faz amplo uso do cruzamento vocabular $(\mathrm{CV})$, processo de formação de palavras que consiste na fusão de duas palavrasmatrizes. Temos, no texto, os seguintes objetivos: (a) analisar os padrões de cruzamento mais frequentemente empregados na construção de ships, seguindo, para tanto, as 
classificações de Gonçalves (2003), Basilio (2005) e Andrade (2013); (b) estabelecer as principais diferenças entre CVs, de um lado, e hipocorísticos de nomes compostos e siglas, de outro, na criação de nomes oriundos da shippagem. Para tanto, utilizamos os trabalhos de Lima (2008) e Abreu (2004, 2009), respectivamente sobre a formação de nomes como "Cadu" (< Carlos Eduardo) e "Procon" (Programa de Proteção e Defesa do Consumidor). Temos, com isso, o propósito de mostrar que as fronteiras entre os diversos processos não concatenativos do português podem ser tênues, sobretudo na formação de ships.

Para tanto, o trabalho se estrutura da seguinte maneira: primeiro, definimos a shippagem para, logo após, apresentar o corpus tomado por base. Na sequência, abordamos brevemente o CV para, por fim, descrever os padrões estruturais utilizados na criação de ships. Concluímos o texto acenando para um continuum entre os processos não concatenativos de formação de palavras na formação de antropônimos, sobretudo os oriundos da shippagem.

\section{Algumas notas sobre o fenômeno da shippagem}

A shippagem é um fenômeno que, nos últimos tempos, vem se popularizando em grande escala, principalmente entre adolescentes nas redes sociais. Como, até onde se conhece, o assunto é pouco conhecido entre morfólogos, dedicamos esta seção a uma descrição mais acurada sobre essa prática muito comum nos dias de hoje.

A expressão constitui decalque do inglês shipping, que ganhou toque mais vernacular ao receber o sufixo-agem. Segundo o blog Holofotes (http://wp.clicrbs.com.br/holofote), o fenômeno se tornou tendência primeiramente na mídia americana, o que justifica a adoção do termo original em inglês. O verbo, por sua vez, provém do encurtamento de relationship, "relacionamento", e logo foi aportuguesado como shippar, o que cria homofonia com o verbo formado a partir de chip ("pequena lâmina usada na construção de transistores"), este grafado com $<\mathrm{ch}>$ e com um único $\langle\mathrm{p}>$, como em "acabei de chipar meu celular".

Como expresso no site Significados, shippar é o ato de torcer pelo envolvimento afetivo de alguém, "normalmente personagens de filmes, seriados, desenhos animados, histórias em quadrinhos, mangás etc." (https://www.significados.com.br/shippar/). Assim, ao praticar a shippagem, o usuário da língua expressa seu desejo de que duas pessoas se envolvam em um relacionamento. Por exemplo, a torcida para que ficassem juntos Afonso e Amália, personagens centrais da novela Deus salve o Rei (Rede Globo, 2017), resultou em "Afonsália", cruzamento vocabular dos antropônimos que nomeiam o par romântico principal da novela. 
- | O fenômeno da shippagem na nomeação de casais: um novo emprego do cruzamento vocabular

Pela shippagem, manifesta-se a expectativa de que uma união afetiva, real ou fictícia, concretize-se. Linguisticamente, a torcida se expressa principalmente pelo cruzamento vocabular, fenômeno que envolve uma combinação não concatenativa ${ }^{3}$ de duas formas de base, a exemplo de "coronaro" (< corona (vírus) + Bolsonaro) e "Micheque" (< Michele (Bolsonaro) + cheque). É ampla, nos últimos 20 anos, a literatura sobre o cruzamento vocabular - tanto em português quanto em outras línguas. Em inglês, o fenômeno é conhecido principalmente como lexical blend (cf. ALGEO, 1977) e, pela sua relevância na formação de palavras em várias línguas, ganhou uma coletânea de quase mil páginas publicada pela famosa editora Mouton de Gruyter (cf. RENNER; MANIEZ; ARNAUD, 2012). Obras muitíssimo recentes são bastante acessíveis pela internet, como Dow (2018), além de Girolamo (2019), por nós enfocada em trabalhos anteriores, no âmbito da interface da fonologia com a morfologia na análise dos blends pela Teoria da Otimalidade (GONÇALVES; CARVALHO; ANDRADE, 2016). No entanto, nessas obras, nada é dito sobre a shippagem ou mesmo sobre a utilização de antropônimos nas mesclagens, razão pela qual não as utilizamos na presente descrição; preferimos trabalhar com os autores brasileiros, muitos dos quais descrevem fusões lexicais envolvendo antropônimos (cf. BASILIO, 2005; ASSUNÇÃO; GONÇALVES, 2008; ANDRADE, 2013, para citar apenas alguns).

$\mathrm{Na}$ tradição sobre o português, é ampla a variação terminológica: palavravalise (ALVES, 1989) e mistura (SÂNDALO, 2001), para citar apenas alguns. No entanto, empregamos, aqui, o termo cruzamento vocabular (CV), utilizado por Sandmann (1985), primeiro manual que abordou o fenômeno (pelo menos até onde se conhece). Na seção "Primeiro olhar sobre o processo de shippagem", descrevemos os cruzamentos com mais vagar, mas, antes, voltemos à questão dos ships.

Na shippagem, dois antropônimos são fundidos numa única forma que remete aos nomes de base. Denominamos de ship o produto do mecanismo da shippagem, como é o caso de "Afonsália", acima mencionado. Por sua vez, o shipper é quem pratica o ato de shippar, ou seja, quem torce pelo casal e nomeia a relação. Por fim, os shippados são as pessoas envolvidas no ship, como Bruna Marquezine e Neymar, nas formas alternantes "Brumar" e "Neymarquezine".

\footnotetext{
3 Em linhas bem gerais, processos concatenativos (ou aglutinativos) consistem no encadeamento de formas e estão diretamente associados à adição; os não concatenativos, por outro lado, são caracterizados por modificação morfofonológica nas bases e nem sempre pressupõem acréscimos. Nos aglutinativos, uma forma pré-especificada (palavra ou afixo) remete a algum tipo de significado e é adjungida ou à esquerda ou à direita de outra. Nos não concatenativos, ao contrário, a própria base sofre modificações fonológicas de natureza variada, não havendo, em consequência, estrito encadeamento de elementos morfológicos: o resultado da operação dificilmente implica uma divisão da palavra em unidades discretas de forma e significado.
} 
A criação de nomes oriundos da shippagem se iniciou com leitores de narrativas de ficção que admiravam determinados personagens, desejando uni-los para que formassem um casal em uma história paralela, já que, na versão original, o par romântico não se constitui. Essas histórias alternativas, criadas por fãs, são nomeadas de fanfics, encurtamento de fanfiction ("ficção criada por fãs"). Além de inventadas pelos fãs, as fanfics são por eles divulgadas, geralmente em sites específicos para esse fim. A página Fanfics Brasil (https://twitter.com/fanfics), por exemplo, é um local virtual exclusivo para a publicação dessas histórias e organiza as mais de 15 mil fanfics em 24 categorias distintas, como aventura, ação, comédia, drama, guerra, LGBT, romance, suspense e terror, entre outras.

O site Spirit Fanfics e Histórias (https://www.spiritfanfiction.com) é uma plataforma popular para autopublicação de histórias em que muitas fanfics são encontradas. A imagem a seguir apresenta o prólogo de uma fanfic desse site. Na postagem, a autora faz um convite para leitores consumirem sua história alternativa da série literária Os heróis do Olimpo. A internauta, identificada como LoveJason, deixa claro que torce para que os personagens Jason e Piper formem um casal, mas, como isso não acontece na história original, ela mesma cria uma história para que seu desejo se torne realidade:

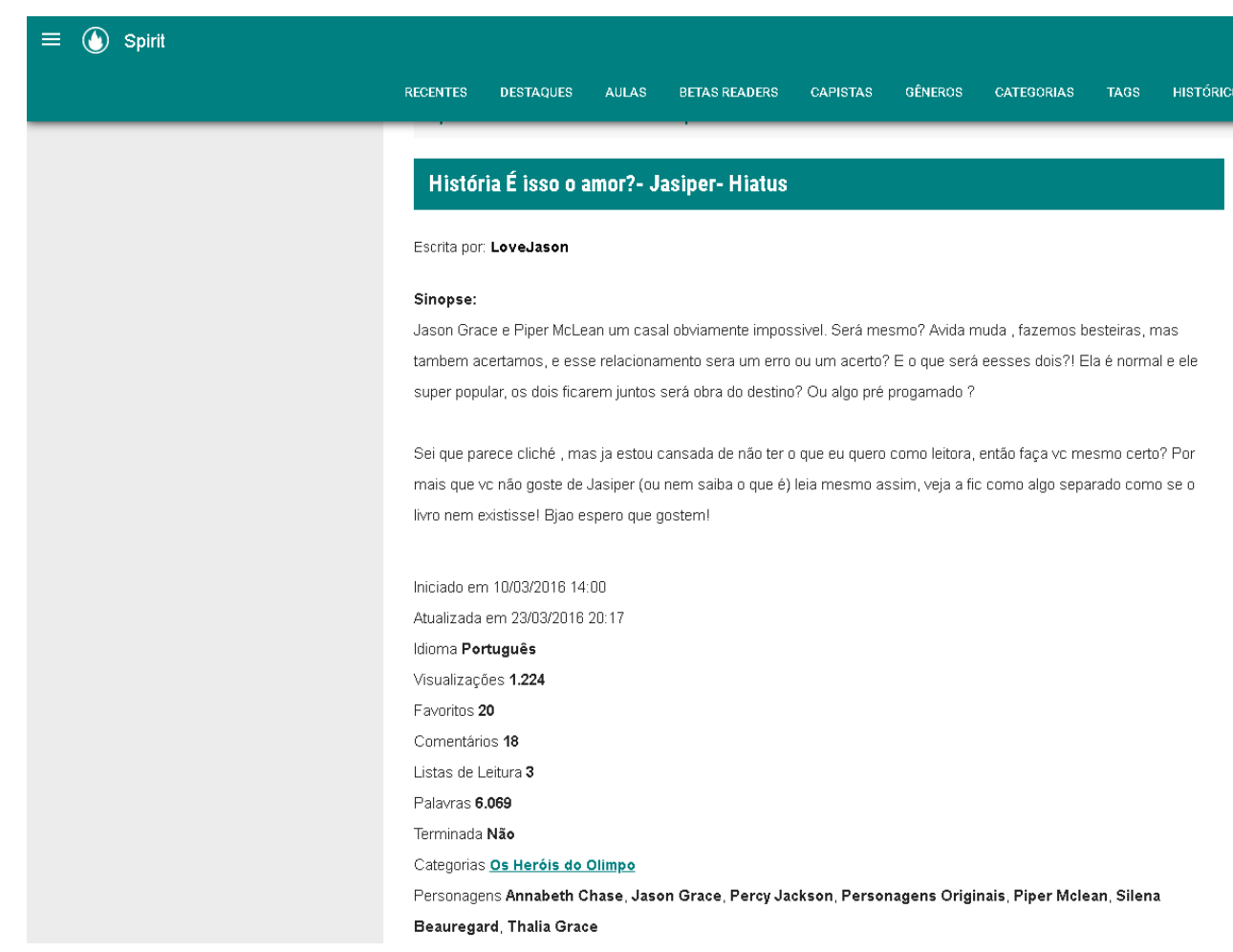

Fonte: https://www.spiritfanfiction.com/historia/jasiper--a-primeira-vez-11360288/capitulo1. Acesso em: 15 mar. 2021. 
- | O fenômeno da shippagem na nomeação de casais: um novo emprego do cruzamento vocabular

Em função de sua ampla popularidade, o fenômeno da shippagem acabou expandindo-se fora da esfera ficcional. Hoje, ships não se referem somente a casais irreais nas histórias, mas também aos de fato encontrados nas narrativas. Além disso, passaram a se reportar também a pares românticos da vida real. Muitos são provenientes de casais famosos, como os já citados "Brumar" e "Neymarquezine". Ao que tudo indica, esses ships foram criados depois de o relacionamento se tornar público, o que comprova que o fenômeno passou a se aplicar a casais já constituídos.

A shippagem também se expandiu para anônimos, ou seja, duplas não famosas nem na vida real nem nas narrativas ficcionais. A imagem a seguir exemplifica essa possibilidade. Na publicação, uma usuária do Facebook tirou uma foto de duas pessoas, João e Lorena, sentadas lado a lado. Depois, expressou publicamente seu desejo de que formassem um casal, cunhando a forma "Jorena":

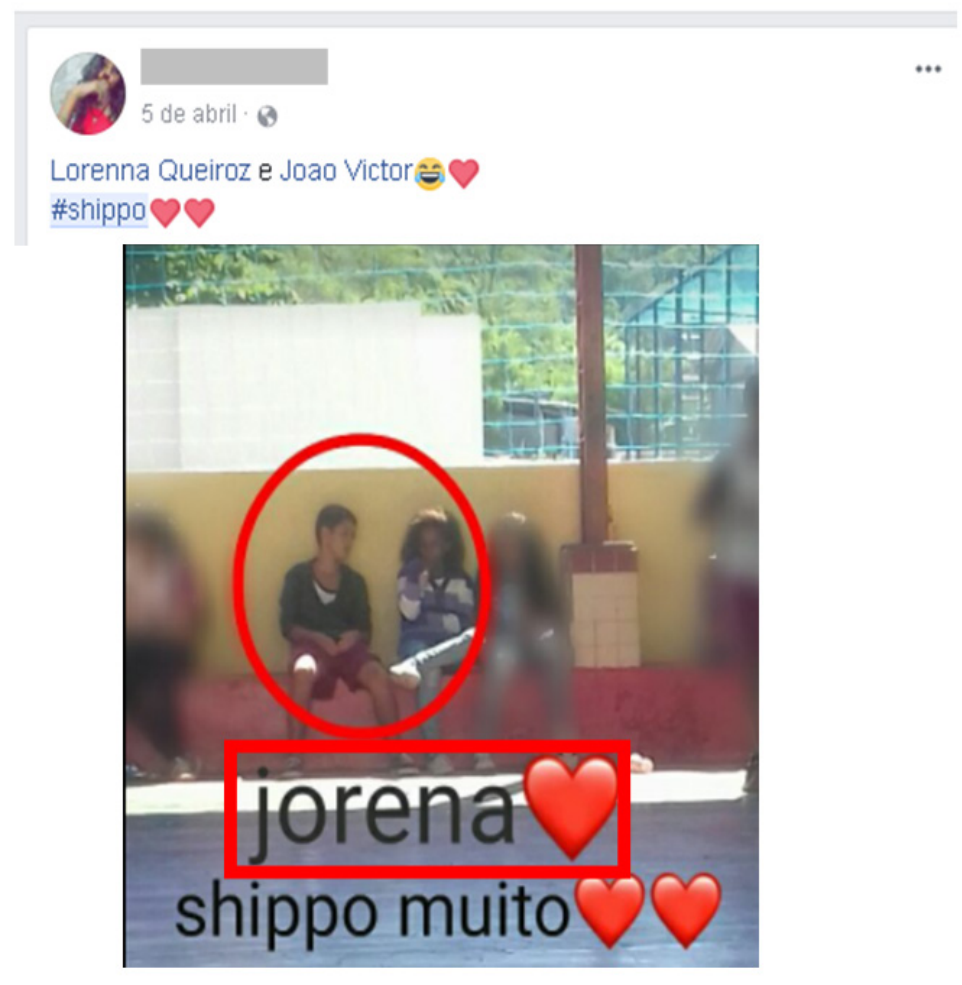

Fonte: https://bit.ly/3FhFyDp. Acesso em: 10 nov. 2017

Há casos em que o ship se origina nos personagens de uma ficção e acaba projetando outro ship, que envolve um casal real, como ocorreu com os personagens Samuel e Marocas, par romântico da novela O tempo não para (Rede Globo, 2018). A expectativa de que Juliana Paiva e Nicolas Prattes começassem um relacionamento gerou o ship "Junick". 
Quanto à previsibilidade da narrativa, os ships referentes a casais da ficção podem ser de dois tipos. Os termos canon ship e conventional couple são usados para casos em que o relacionamento pelo qual se torce é óbvio na história, de maneira que o autor não deixa dúvidas de que determinados personagens ficarão juntos na trama. Já cult ship ou unconventional couple é o oposto, pois se realiza quando um par romântico nunca é revelado pelo autor ao longo da narrativa.

Em relação ao gênero do casal, os ships recebem diferentes classificações. O termo slashship é usado para casais formados por personagens homossexuais masculinos, enquanto femslashship é a expressão usada em referência a casais formados por personagens homossexuais femininos, o que nos leva à conclusão de que, quando não especificado (ou não marcado, fazendo relação com o gênero gramatical), o ship se refere a casais heterossexuais.

Além dessas classificações, o site Amino (https://aminoapps.com) descreve o ship de amizade que, em vez de representar uma torcida para que os shippados se tornem um casal, expõe apoio pela parceria entre duas pessoas ou o desejo de que se tornem amigas, como é o caso de "Semi", mescla de Selena Gomes e Demi Lovato, atrizes e cantoras norte-americanas.

De acordo com um site geek (http://www.garotasgeeks.com), há, ainda, três outras possibilidades de classificação dos ships. OTP é a sigla da expressão inglesa One True Paring ("único casal verdadeiro"), termo atribuído ao ship do casal favorito. Ghost ship, por sua vez, remete a pares românticos cujos personagens morreram ao longo da narrativa. Por fim, crack ships são aqueles que misturam personagens de histórias diferentes, o que os torna improváveis. O fato de um casal ser improvável - ou até impossível - não inibe a torcida. A revista Capricho, voltada especificamente para adolescentes do sexo feminino, divulgou matéria sobre o assunto, listando doze casais improváveis, mas, ainda assim, shippados. A revista deixa claro que não há regras quanto a isso e afirma o seguinte: "nem todos os casais que shippamos vão acontecer. Ou porque eles nunca tiveram nada além de amizade ou porque já não tem mais nada a ver juntos. Mas no maravilhoso mundo dos shippers tudo é possível!" (https://capricho.abril.com.br/vida-real/nem-ai-13-casais-quevamos-shippar-hoje-amanha-e-sempre). Obviamente, esses dados não compõem nosso corpus, por terem sido criados com o objetivo de mostrar os limites entre o que pode e o que não pode acontecer num ship.

\footnotetext{
4 Geek é uma gíria da língua inglesa que nomeia alguém viciado em tecnologia, computadores e internet. Uma pessoa geek é semelhante a um nerd: tem profundo interesse por assuntos científicos e tecnológicos, gosta de estudar, é muito inteligente, pouco sociável e não se importa com a aparência pessoal.
} 
- | O fenômeno da shippagem na nomeação de casais: um novo emprego do cruzamento vocabular

Em redes sociais, como o Instagram, o Twitter e o Facebook, ships são frequentemente acompanhados de hashtag (\#), ferramenta que facilita a busca de outras postagens sobre o assunto. Dessa forma, a hashtag e o ship possibilitam o encontro de pessoas que tenham interesse específico na torcida por um mesmo casal. Não é incomum o fato de pessoas que compartilham o mesmo interesse se juntarem para formar torcidas organizadas, visto que a existência de fãs clubes é anterior ao fenômeno da shippagem. Existem sites, inclusive, cuja função principal é conectar pessoas que compartilham do mesmo gosto, como o já comentado Amino.

A popularização da shippagem gerou diversas brincadeiras, a exemplo do desafio lançado pela página Buscapé no Facebook no dia dos namorados, 12 de junho de 2018. Nesse desafio, os internautas foram estimulados a criar ships de seu próprio casal, ou seja, unir seu nome com o do(a) cônjuge ou namorado(a). As perguntas feitas na página foram "Qual é o seu nome de casal?" e "Como ficaria se você juntasse seu nome com o do mozão?". Na imagem a seguir, aparecem algumas respostas:

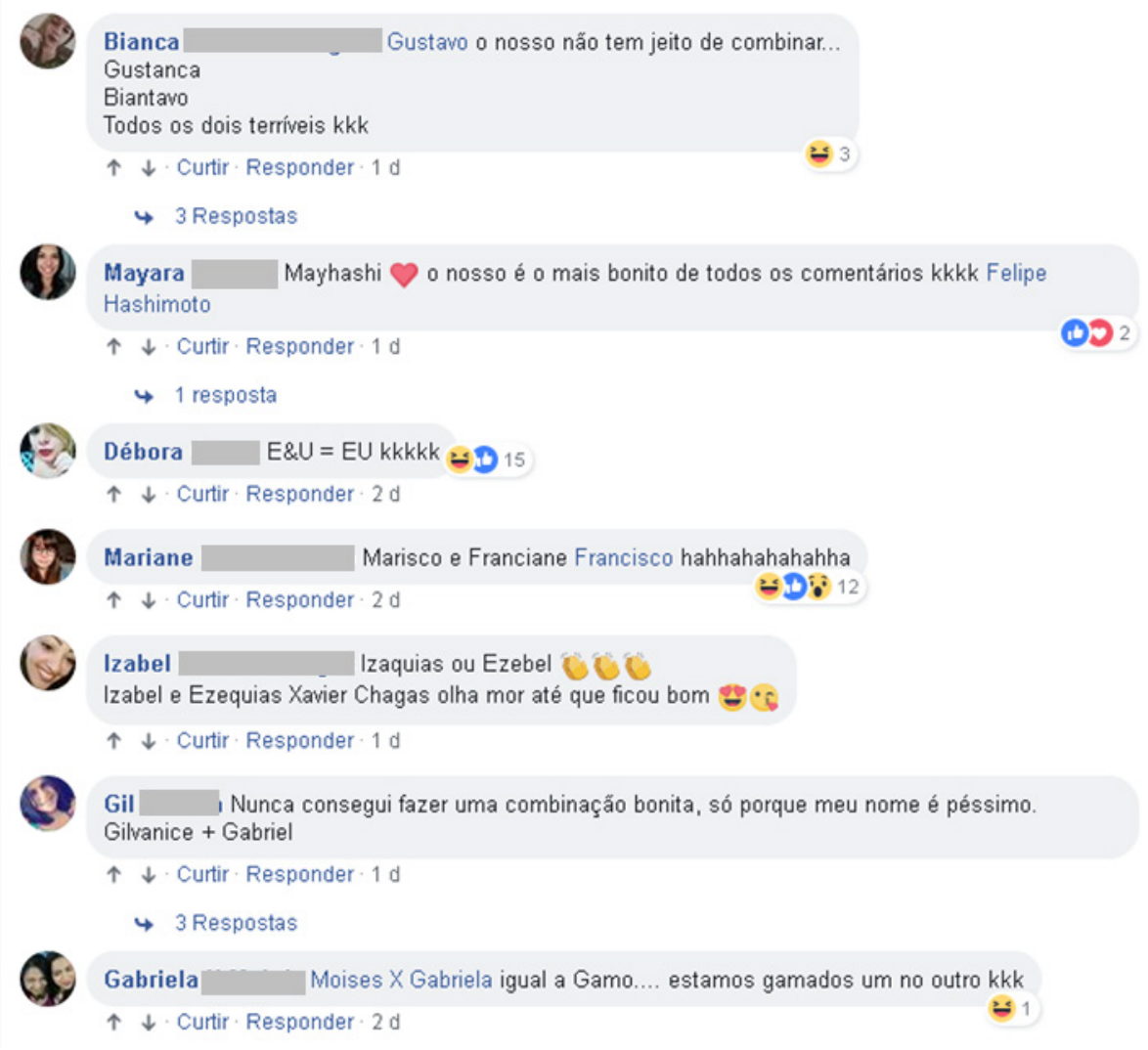

Fonte: https://bit.ly/3EdvVnH. Acesso em: 20 jun. 2018. 
Nos exemplos formados, fica claro o alto grau de monitoramento com que ships são cunhados. Em caso de repercussão negativa, o shipper busca nova alternativa de junção, geralmente trocando a ordem das bases, como ocorre em "Gustanca" ou "Biantavo" para Gustavo mais Bianca; "Marisco" ou "Franciane" para Mariane mais Francisco; e "Izaquias" ou "Ezebel" para Izabel mais Ezequias. Houve, nas postagens, um caso em que o internauta julgou ruins todas as alternativas pensadas para Gilvanice mais Gabriel, preferindo, assim, não registrar nenhuma.

Além de páginas para produzir possíveis combinações de antropônimos, também são encontradas na internet enquetes envolvendo ships, como a votação no Blog do Mauricio Stycer (https://tvefamosos.uol.com.br/blog/mauriciostycer) sobre quem deveria ficar com a personagem Eliza, da novela Totalmente Demais (Rede Globo, 2015). As opções da votação foram fechadas, Artur ou Jonatas, que originaram os ships "Arliza" $(<$ Artur + Eliza $)$ e "Joliza" $(<$ Jonatas + Eliza $)$.

A crescente popularidade da shippagem resultou até na criação de algoritmos produtores de ships. Existem aplicativos disponíveis no Google Play e sites que geram ships, tendo o usuário apenas de escrever o nome dos dois integrantes do (possível) casal. O Fandom Ship Names Generator é gratuito e cria várias opções de ships. As alternativas oferecidas são diversas, mas, em muitas, não é possível reconhecer os antropônimos originais; em outras, aparecem sequências segmentais totalmente em desacordo com os padrões fonotáticos da língua. Para a entrada Bianca e Gustavo, por exemplo, são disponíveis opções como "Ag", "Agustav", "Ancag", "Bgustav", "Biancgu", "Caustavo", "Gustavb", "Iancatavo", "Ncagu", entre outras. Obviamente, esses dados não foram objeto de análise neste artigo por terem sido criados artificialmente (por programa de computação). A seguir, apresentamos o corpus utilizado na pesquisa para, logo após, analisar os padrões estruturais utilizados na criação de ships.

\section{O corpus}

Nosso corpus é constituído de 212 dados. Com exceção de 10 dados coletados de fala espontânea, todos os demais foram retirados da internet. A maioria dos ships coletados remete a programas de televisão ou a plataformas on-line de filmes, séries (como as da Netflix) e novelas. As principais fontes são os sites que falam sobre personagens e atores dessas narrativas, como revistas, jornais, fanfics, blogs diversos, além das redes sociais Twitter, Facebook e Instagram.

Cento e vinte ships (56\% dos dados) referem-se a casais na vida real, quantitativo que comprova ter a shippagem se expandido para além das narrativas de ficção. Desses ships de pares românticos, 
- | O fenômeno da shippagem na nomeação de casais: um novo emprego do cruzamento vocabular

(i) 33 são de anônimos e foram coletados principalmente das redes sociais, como "Brelherme", união de Brenda e Guilherme;

(ii) 29 nomeiam participantes do Big Brother Brasil e d'A Fazenda (reality shows brasileiros), como "Brenara", junção de Breno e Ana Clara;

(iii) 24 são de atores e atrizes, a exemplo de "Judrigo", mescla de Juliana Paiva e Rodrigo Simas;

(iv) 12 envolvem personalidades do campo musical (cantores, instrumentistas etc.), como "Luade", oriundo de Luan Santana e Jade Magalhães;

(v) 2 são do domínio jornalístico (dois ships com as mesmas bases): "Sandrevaristo" e "Evarisandra", união de Sandra e Evaristo, prenomes dos então apresentadores do Jornal Hoje (Rede Globo, 2016);

(vi) 1 diz respeito a youtubers: "Viihlu", mescla de Viih e Luiz;

(vii) 1 vem da esfera política: "Marchele", fusão de Marcela (Temer) com Michele (Bolsonaro);

(viii) 18 remetem a shippados que não possuem a mesma função, a exemplo de "Felena", de Fausto Silva, apresentador de televisão, e Selena Gomes, atriz.

Os outros 92 dados, que correspondem a casais da ficção, são distribuídos em:

(i) novelas brasileiras (42 casos), a exemplo de "Shirlipe", junção de Shirlei e Felipe, da novela Haja coração (Rede Globo, 2016);

(ii) séries internacionais (36 ships), como "Stelena", união de Stefan e Elena, da série The vampire diaries;

(iii) filmes (8 nomes), como "Dramione", cruzamento de Draco com Hermione, do filme do Harry Potter;

(iv) mangás (4 dados), a exemplo de "Nalu", de Natsu e Lucy, do mangá Shonen;

(v) livros (2 casos), como "Jasiper", mescla de Jason e Piper, do livro Percy Jackson e os Olimpianos.

Quanto à relação interpessoal expressa nos ships, 205 dados manifestam apoio por um casal contra apenas 7 de amizade, o que confirma ser a relação romântica o principal domínio conceptual da shippagem. Dos 205 ships de casais, 89\% (183 dados) são de casais heterossexuais, enquanto 7\% (13 dados) são classificados como slashship, 
ou seja, casais homossexuais masculinos, e 4\% (9 dados) são de femslashship, casais homossexuais femininos. Exemplo de slashship foi retirado de um blog sobre Sherlock Holmes, clássico personagem da literatura britânica, que, segundo o blogueiro, mantém um suposto romance com seu assistente John Watson, o que motivou o ship "Jonhlock" (http://sherlockbrasil.blogspot.com.br). Exemplo de femslashship é "Clanessa", mescla de Clara e Vanessa, nomes de duas participantes da 14ª edição do Big Brother Brasil (2014).

Por definição, ships pressupõem bases antroponímicas, aqui entendidas como manifestações de termos referentes à onomástica ${ }^{5}$ : prenomes, sobrenomes, hipocorísticos, alcunhas ou nomes artísticos. Na maioria dos casos, ships resultam da união de dois prenomes, como "Thiara" (<Thiago + Sara). Quando o prenome é composto, o shipper pode selecionar a primeira ou a segunda forma para produzir a mescla. Como exemplo, podemos citar dois ships envolvendo Ana Clara, nome de uma participante do Big Brother Brasil 17. No caso do cruzamento com o antropônimo Breno, o ship resultante é "Breana", com a opção pelo primeiro nome, Ana; já no caso da mescla com o prenome Caruso, o produto é "Claruso", sendo selecionado o segundo nome, Clara.

Em alguns dados, faz-se uso de sobrenomes. No caso de "Tralliane" $\quad<$ Tralli + Ticiane), o cruzamento envolve o sobrenome do jornalista Cesar Tralli com o prenome da apresentadora Ticiane Pinheiro. Em "Stylinson", foram mesclados dois sobrenomes, os dos músicos Harry Styles e Louis Tomlinson, ambos da banda One Direction.

Além de envolver prenomes e sobrenomes, ships podem acessarbases hipocorísticas, como "Cabibi", de Caio e Bibi, personagens principais da novela A força do querer (Rede Globo, 2017). Os dois únicos casos em que uma das entradas não constitui antropônimo são "Dolly", cruzamento de Doutor Marcos com Emilly, nomes de participantes do reality show BBB 17 (Rede Globo, 2017), e "Captain Swan", mescla de Captain Hook com Emma Swan, personagens da série Once upon a time.

Uma vez discriminado o corpus, passemos, na sequência, à descrição estrutural dos ships. Pretendemos, portanto, apresentar os principais aspectos fonológicos e morfológicos desse tipo de construção, investigando as motivações para a ordem das bases no interior do cruzamento e o tipo de CV mais utilizado na nomeação de casais. Para isso, definimos, ainda que brevemente, esse processo de formação de palavras.

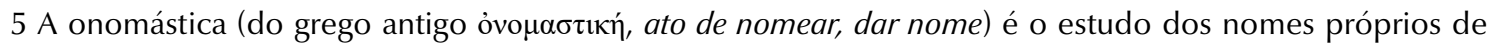
todos os gêneros, das suas origens e dos processos de denominação no âmbito de uma ou mais línguas ou dialetos. 
- | O fenômeno da shippagem na nomeação de casais: um novo emprego do cruzamento vocabular

\section{Outras notas sobre o cruzamento vocabular}

O cruzamento vocabular pode ser definido como um processo não concatenativo de formação de palavras que consiste na mesclagem de duas bases (cf., p. ex., LEHRER, 2007, DOW, 2018; GIROLAMO, 2019), como em "sapatênis" (junção de sapato com tênis, "tipo de calçado"), "feminazi" (mistura de "feminista" com "nazista", "referência pejorativa, ofensiva e tóxica à militância feminina pela igualdade de direitos") e "boaconha" (junção de boa com maconha; "maconha de boa qualidade, sem mistura, pura"). Alves (1989) denomina o produto de palavra-valise, uma vez que resulta da união de pedaços de duas outras palavras. Marginal até os anos 1990, o CV vem recebendo amplo tratamento na literatura em diversas linhas teóricas, como mostramos em texto ainda no prelo, intitulado "Por uma visão compreensiva do cruzamento vocabular em português" (GONÇALVES, 2021). Como nosso interesse específico é no fenômeno da shippagem, que faz amplo uso do CV, iremos abordá-lo basicamente focalizando seus diferentes tipos, propostos por Gonçalves desde 2003. Tal classificação é corroborada em trabalhos como Basilio (2005), Andrade (2008), Carvalho (2008), Andrade (2013) e Rio-Torto (2014), para citar apenas alguns. Apesar da grande variação terminológica existente, vamos usar o termo mais consagrado na literatura: cruzamento vocabular (cf. GONÇALVES, 2021), CV.

CVs podem ser distribuídos em três grandes grupos de processos de formação de palavras. O primeiro deles - e o mais produtivo nos cruzamentos de nomes próprios (cf. BENFICA da SILVA, 2019) - é o entranhamento lexical, mecanismo que consiste na fusão de duas palavras pela interposição de uma a outra. Do ponto de vista fonológico, as duas bases são literalmente superpostas, de modo que um ou vários segmentos ${ }^{6}$ são compartilhados:

(01) aborrescente (<aborrecer + adololescente)

alcoolância (<álcool + ambulância)

craquético $(<\underline{\text { craque }}+\underline{\text { caquético }})$

crionça $(<\underline{\text { criança }}+\underline{\text { onça }})$

escragiário (<escravo + estagiário $)$

Os dados revelam que as bases compartilham idêntica estrutura segmental (sílabas, rimas ou mesmo porções fônicas não equivalentes a categorias de análise fonológica, como pés métricos) e se fundem de tal modo que geram, no nível de palavra resultante, inúmeras relações de correspondência de um-para-muitos entre a forma cruzada e as formas de base. Na grande maioria dos dados, os itens envolvidos não são do mesmo

6 O termo segmento é aqui utilizado em referência às unidades sonoras (sons da fala) das palavras de base, também chamadas de matrizes lexicais (RONNEBERGER-SIBOLD, 2013; LIEBER, 2005). 
tamanho. Quando isso acontece, a palavra mais curta aparece maximamente representada na forma resultante, não sofrendo, portanto, nenhuma perda segmental, como em "mautorista" e "boilarina". A forma de base mais longa, embora seja caracterizada pela perda de segmentos, contribui, no $\mathrm{CV}$, com suas estruturas métrica (divisão em pés) e acentual (proeminência na mesma sílaba). Em vários casos de entranhamento lexical, o número de sílabas e a pauta acentual da base mais longa correspondem ao número de sílabas e à acentuação da forma cruzada, a exemplo do que ocorre com "familícia", "crentino" e "marginata".

O segundo subprocesso de CV é a combinação truncada, que, em geral, não faz uso da ambimorfemia (compartilhamento de material fonológico), uma vez que são raros os casos em que não há qualquer semelhança fônica entre as bases. Quando as palavras não são do mesmo tamanho, a maior sofre encurtamento e a menor se concatena a ela ("lambafunk", "futivôlei"). Quando as duas apresentam equivalente número de segmentos, há redução em ambas ("portunhol", "brasiguaio"). De um modo geral, o significado do produto corresponde a uma combinação quase sempre transparente dos significados de ambas as palavras. Tal é o caso de "depuvid", em que as duas palavras são truncadas (deputado e Covid), e "presijegue", forma em que apenas uma das bases é encurtada (no caso, presidente). Esses CVs são mais designativos do que expressivos, ou seja, neles predomina a função de rotulação, enquanto no entranhamento sobressai a função atitudinal (expressão de ponto de vista):

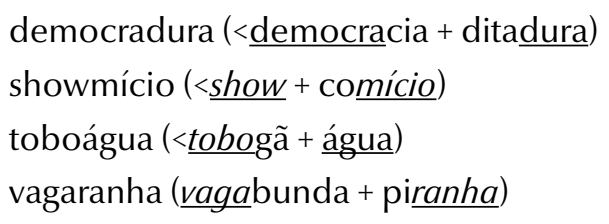

O último fenômeno relacionado ao CV é a reanálise. Nesse caso, uma sequência fonológica de uma das palavras é interpretada morfologicamente e substituída. Gonçalves, Andrade e Almeida (2010) descrevem tais casos como substituições sublexicais (SSLs). Nas SSLs, uma palavra - por conta da relação formal e semântica que parte dela mantém com outra - é entendida como morfologicamente complexa e, consequentemente, reestruturada em função dessa identidade. Em comemorar, por exemplo, a primeira parte do verbo (come) é interpretada como se estruturasse a partir do radical de comer, já que comemorações remetem ao frame de festa: são eventos descontraídos em que normalmente se oferecem "comes e bebes". A formação analógica bebemorar, já bastante consagrada pelo uso e catalogada no dicionário eletrônico Aurélio — séc. XXI, designa, expressivamente, uma situação de festejo regada a bebida. Passemos, enfim, à descrição dos aspectos fonológicos e morfológicos relevantes à formação de ships. 
- | O fenômeno da shippagem na nomeação de casais: um novo emprego do cruzamento vocabular

\section{Primeiro olhar sobre o processo de shippagem}

Ao contrário de outras formações envolvendo nomes de pessoas, como "bolsonero" (GONÇALVES, 2020) e "malalfafa" (GONÇALVES, 2019b), usados em referência a Jair Bolsonaro e Silas Malafaia, respectivamente, os dados não apresentam bases predicadoras, mas antropônimos interligados. Se, nesses casos, há clara relação de subordinação entre as bases (cf. BENFICA da SILVA, 2018), na shippagem, ao contrário, ocorre coordenação. Considerando a noção da sintaxe da palavra, proposta por Sandmann (1989), ships são sempre copulativos, como atestam os exemplos a seguir, em que a sílaba tônica é negritada:

$$
\begin{aligned}
& \text { Bentriz - '트to e Beatriz' } \\
& \text { Jorena - 'Loão e Lorena' } \\
& \text { Peloísa - 'Pedro e Heloísa' }
\end{aligned}
$$

Ao que tudo indica, a ordem das bases no interior dos ships é determinada por

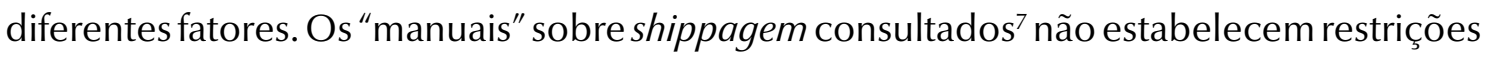
quanto à ordem que as bases devem seguir. Por exemplo, não há ressalvas se é o nome da mulher ou o do homem que deve vir antes no ship, até mesmo porque ships podem envolver pessoas do mesmo gênero, como ressaltamos na segunda parte do texto. A coleta de dados aponta para uma escolha baseada na sonoridade mais agradável do produto final, tanto que, na etapa de produção do ship, muitos falantes testam as duas ordens, A + B ou B + A, e escolhem a que "combina mais", ou a que "fica mais bonita", expressões usadas pelos criadores ao justificar o que se conhece na literatura como eufonia ${ }^{8}$. As imagens a seguir demonstram a dupla tentativa de ordenação das bases.

\footnotetext{
7 O termo manual deve ser tomado aqui em sentido bem amplo e, por isso mesmo, está entre aspas. São, na verdade, páginas da internet que se dedicam a "ensinar" os usuários a compor nomes de casais, ou seja, a shippar. Entre os consultados, estão os seguintes:

Diário secreto: http://diario-otome.blogspot.com/2018/06/manual-da-shippagem-o-que-e-shippar.html; Funcfiction Net: http://diario-otome.blogspot.com/2018/06/manual-da-shippagem-o-que-e-shippar.html Segunda espécie, ou Bella cria um par: http://diario-otome.blogspot.com/2018/06/manual-da-shippagem-oque-e-shippar.html.

8 Qualidade acústica favorável da emissão e/ou da audição de um significante pela articulação de certos fonemas. No domínio fônico, a eufonia procura evitar sons estranhos, contrastantes, discordantes, repetições desagradáveis; em fonética, explica certas mudanças, podendo ser fator de assimilação ou de dissimilação (Wikipédia. Disponível em: https://pt.wikipedia.org/wiki/Eufonia. Acesso em: 10 out. 2020).
} 


\section{Tatiana Kelana ou tatelson? Kelson kk $=$

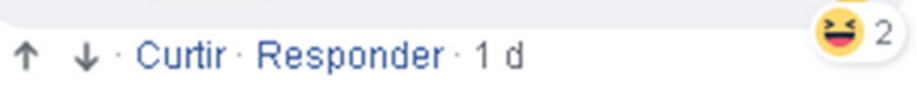

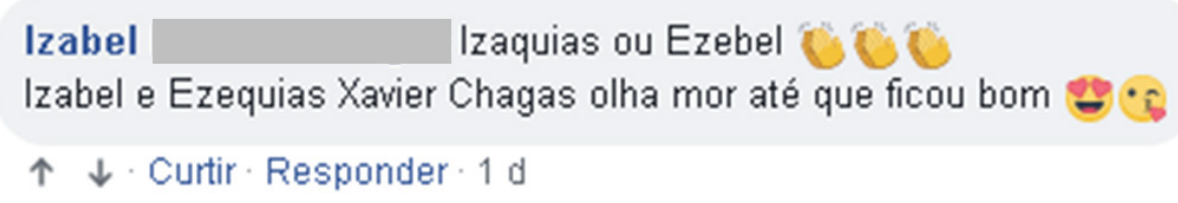

\section{Bianca} Gustavo o nosso não tem jeito de combinar..

Gustanca

Biantavo

Todos os dois terriveis kkk

$\uparrow \downarrow \cdot$ Curtir $\cdot$ Responder $1 d$

Fonte: https://bit.ly/32ugudS. Acesso em: 10 jun. 2018.

Um questionamento instigante que se tenta responder no estudo do cruzamento vocabular é como definir, entre as duas bases, qual delas será a primeira (cf. PIÑEROS, 2002; ANDRADE, 2008). No caso da shippagem, podemos aplicar o questionamento, por exemplo, às seguintes perguntas: (a) por que o ship de Afonso e Amália é "Afonsália" e não Amalionso? Por que o de Rodolfo e Brice é "Bridolfo" não Rodolce? O caminho para as respostas perpassa, para nós, os seguintes aspectos: (a) o rastreamento das formas de base a partir dos ships, o que é garantido, por um lado, pela menor perda de massa fônica e (b) o melhor efeito sonoro (no sentido de eufonia) da forma criada. Essas hipóteses, por sua vez, geram outro questionamento: por que "Afonsália" e "Bridolfo" são mais bem-sucedidas do que Amálionso e Rodolce e, por isso mesmo, emergiram como os verdadeiros ships dos casais ora considerados?

Análises do CV por ranking de restrições, nos moldes da Teoria da Otimalidade (cf., p. ex., ANDRADE, 2008; GONÇALVES; CARVALHO; ANDRADE, 2016), comprovam que ser fiel às bases e não criar formas que possam evocar outras, fora da esfera das que estão sendo combinadas, têm alta prioridade na língua. Desse modo, "portunhol" supera "espaguês", na análise de Gonçalves (2006), não apenas porque esta deixa de priorizar posições prosodicamente proeminentes, como teremos a oportunidade de abordar adiante, mas porque aproveita de "português" justamente a porção que contém um morfema (o sufixo ês) e lembra outra forma da língua, "espaguete", o que levou os informantes do teste aplicado por Gonçalves e Salgado (2006, p. 198) a rechaçar essa 
- | O fenômeno da shippagem na nomeação de casais: um novo emprego do cruzamento vocabular

forma, por "não ter pronúncia agradável", como relatado pelo informante designado por B. Assim, quando nos referimos a "melhor efeito sonoro", estamos falando de situações em que uma combinação possível gera uma forma "estranha", o que Basilio (2005) denomina de fusão vocabular expressiva mal sucedida.

Ao selecionar uma forma, em detrimento de outra, o shipper utiliza sua intuição de falante nativo. Podemos recorrer a Basilio (2005), para quem a chave da interpretação do CV consiste em reconhecê-lo como palavra alterada no todo (e não pela soma de suas partes de palavras). Nesse sentido, é mais fácil rastrear a base Afonso no ship "Afonsália" que em Amálionso, do mesmo modo que o acesso a Brice é maior em "Bridolfo" que em Rodolce: a maior quantidade de material fônico preservada possibilita rastrear melhor as formas de base. Outro fator extremamente importante é a manutenção da estrutura métrica (número de sílabas) e prosódica (padrão acentual) das palavras-matrizes.

Podemos recorrer à proposta de fidelidade posicional de Beckmann (1998), para quem existe um pequeno inventário de posições linguisticamente privilegiadas que desempenham papel importante nos sistemas fonológicos. Essas posições são as que apresentam vantagem perceptual no sistema de processamento, via proeminência psicolinguística ou fonética, em relação a posições não privilegiadas: sílabas iniciais de raízes/palavras, sílabas acentuadas, onsets silábicos, raízes, vogais longas. Tomemos o caso de "Bridolfo" e "Rodolce", possíveis ships para o casal Brice e Rodolfo. Vejamos a estrutura métrico-prosódica das duas formações. Nessas representações, os símbolos PWd, $\sigma, \sum$ representam, nessa ordem, a palavra prosódica, a sílaba e o pé (nos dois casos, um troqueu) - as categorias mais baixas da hierarquia prosódica:

(04)

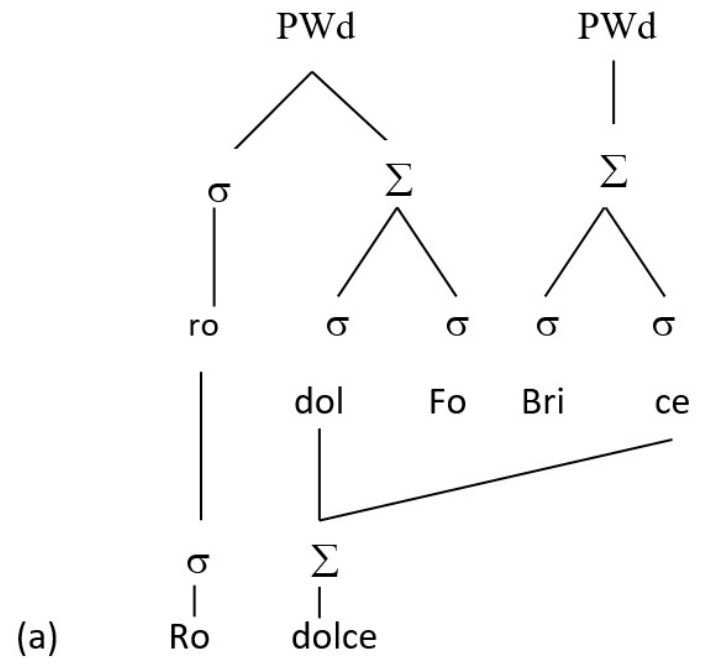

(05)

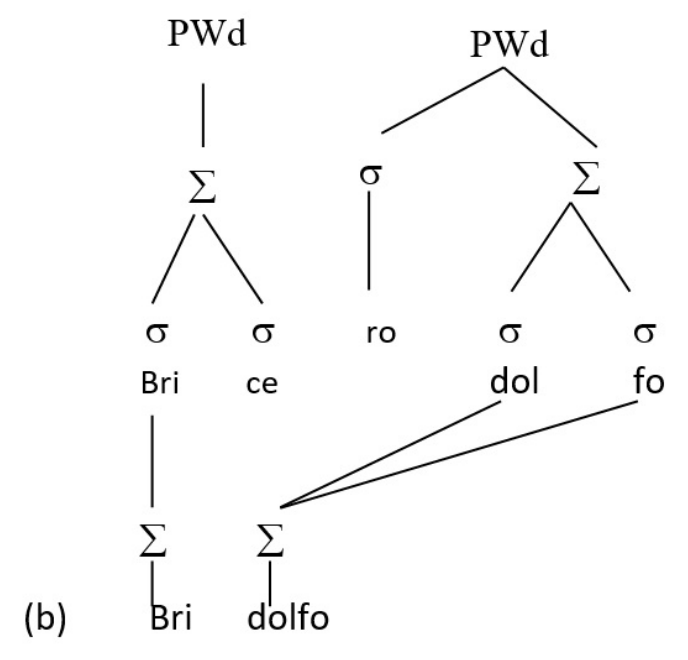


Raciocínio semelhante vale para o possível (mas não identificado ship) "Amalionso". Se, por um lado, o prenome Amália está bem representado no ship, o mesmo não se pode dizer a respeito de Affonso. Apesar do aproveitamento do pé trocaico nuclear quase na íntegra (só o /f/ não é levado para a forma ora inventada), a sequência onso não constitui sufixo, mas aparece em palavras muito usuais da língua, como "sonso", além de lembrar um possível masculino de "onça". Esses fatos justificariam a ordem das palavras no interior dos ships. Observe a representação de "Affonsália", o ship criado para a torcida de Affonso e Amália na novela Deus salve o rei (Rede Globo, 2017). Na representação abaixo, MWd faz referência à palavra morfológica (morphological Word) e $\mathrm{MWd}^{*}$ à palavra morfológica complexa. O e R abreviam os constituintes silábicos onset e rima (optamos por deixar os dois $<f>$ de Affonso apenas para ser fiel à grafia original desse antropônimo:

(05)

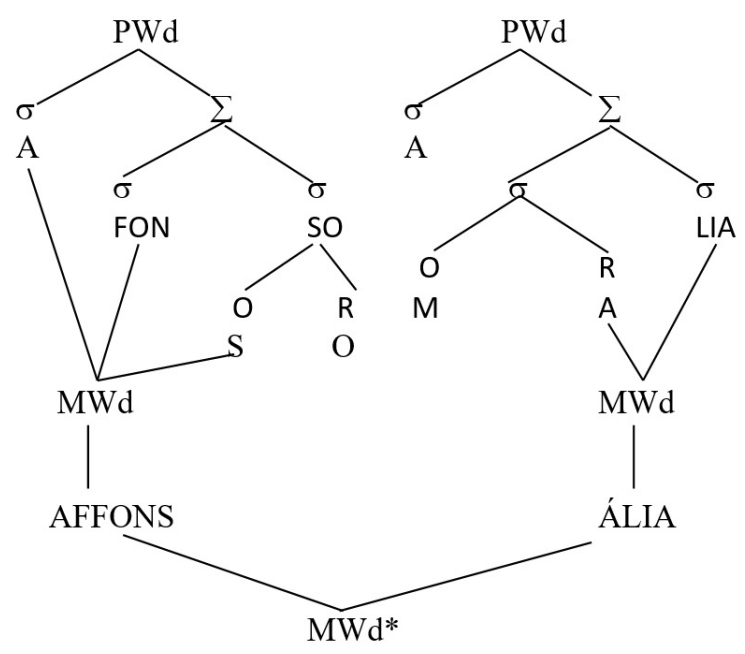

Como se vê, ships se valem de cruzamentos inclusive no que diz respeito à ordem das bases no interior do produto. Observam-se, em (05), duas posições prosodicamente proeminentes envolvidas: o pé nuclear (de Amália) e a margem esquerda (de Affonso). O menor número possível de apagamentos também é levado em consideração: somente a vogal átona final de Affonso e átona inicial de Amália não aparecem no produto. Se considerarmos a ambimorfemia de elementos não idênticos, como Piñeros (2002), é possível associar [f] com [m], dada a posição estrutural de onset e o grau de semelhança fônica entre os segmentos (ambos são labiais).

Quanto à estrutura dos ships, identificamos ao todo cinco possibilidades de formação, sendo apenas duas consideradas mais padronizadas, pois as outras três não se mostram tão regulares e não apresentam número significativo de ocorrências (tokens). $\mathrm{O}$ padrão dominante é o que mescla os segmentos iniciais da primeira base com os finais 
- | O fenômeno da shippagem na nomeação de casais: um novo emprego do cruzamento vocabular

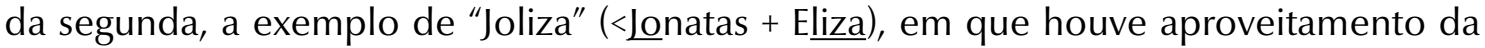
borda esquerda de Jonatas e do pé nuclear de Eliza, duas posições salientes do ponto de vista perceptual (BECKMANN, 1998). A grande maioria (85\% dos dados, 180 formações) foi criada por esse padrão. Mais alguns exemplos aparecem em (06), a seguir.

(06) Belidolfo ( $<$ Beliza + Rodolfo $)$

Brenlherme $(<$ Brenda + Guilherme $)$

Paugner $(<$ Paula + Wagner $)$

Shirlipe $(<\underline{\text { Shirlei }+ \text { Felipe })}$

Thiara $(<\underline{\text { Thiago }}+$ Sara $)$

O segundo modelo identificado no corpus é o que mescla a margem esquerda de ambas as bases, a exemplo de "DiRo" ( $<$ Diego + Roberta). Apenas 13\% dos ships (28) são formados por esse padrão, que parece não se repetir no cruzamento vocabular formado por nomes comuns, os quais geralmente seguem a estrutura de "portunhol" (<português + espanhol) e "chocotone" (<chocolate + panetone) - (cf. GONÇALVES, 2003; BASILIO, 2005; ANDRADE, 2008), p. ex., o que confirma a relevância do pé na formação dos produtos. A seguir são listados mais alguns ships formados pelas margens esquerdas das formas de base, o que põe em relevo, por sua vez, a importância da sílaba e do início de palavras, posições também privilegiadas, na visão de Beckmann (1998).

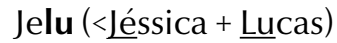

$$
\begin{aligned}
& \text { MaVi ( }<\text { Manoel + ivian })
\end{aligned}
$$

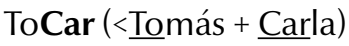

Como se vê nos dados, essas formas se assemelham mais a hipocrísticos de nomes compostos do que a cruzamentos, uma vez que, como demonstra Lima (2008), esse fenômeno define-se como a junção de duas bases antroponímicas que se encurtam, a exemplo de "Malú" de Carlos André. Além disso, o processo em questão cria formas que são, de maneira geral, oxítonas,ou seja, constituídas de um único pé iâmbico (. *). A exceção à regra se faz com os hipocorísticos terminados em [a]; nesse caso, serão sempre paroxítonos, constituindo, assim, pés trocaicos, como se observa nos exemplos em (08):

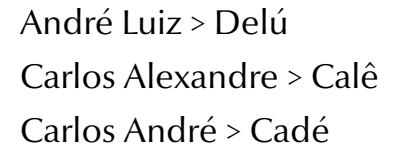

9 Representamos os acentos neste e nos demais exemplos com os sinais gráficos vigentes apenas com o propósito de indicar as tônicas, a despeito de serem ou não grafadas dessa maneira pelos padrões de escrita do português. 


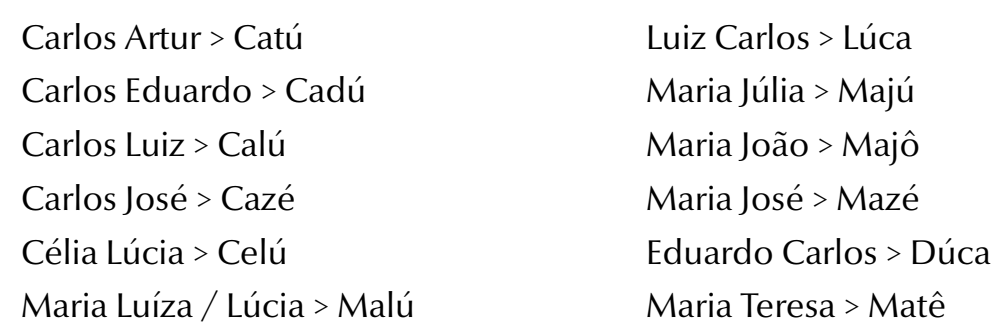

Os dados em (08) confirmam o que foi dito anteriormente: à exceção dos hipocorísticos terminados em [a], que são sempre paroxítonos, todos os demais são oxítonos (por isso, usamos acentos gráficos para marcar as tônicas). Além disso, observase que, em quase todos os casos, a primeira sílaba com onset do primeiro nome é unida à primeira sílaba com onset do segundo, constituindo o hipocorístico. As exceções estão nos casos em que aparece o antropônimo José. Nesses hipocorísticos, a sílaba <zé> será sempre copiada, e nunca a primeira sílaba com onset (<jo >), como nos demais $\operatorname{casos}^{10}$. Como se vê, é muito semelhante o padrão de hipocorização ora em foco com os dados em (07), o que os torna mais próximos de hipocorísticos do que de cruzamentos, muito embora a função dos ships seja bem diferente da de hipocorísticos (ships nomeiam; hipocorísticos são expressivos). Do ponto de vista fonológico, no entanto, é próxima a relação desses ships com hipocorísticos de nomes compostos. Por outro lado, quando se observam os dados a seguir, o processo mais semelhante passa a ser a siglagem:

$$
\begin{aligned}
& \text { a. BelGra (< } \text { Belo + Gracyanne) } \\
& \text { b. Jolari (ЦLõo + Larissa) } \\
& \text { c. Peromar (Pérola + Márcio) }
\end{aligned}
$$

A formação (09a) destoa dos hipocorísticos de nomes compostos em três aspectos importantes: (a) não forma um troqueu (mas um iambo), embora o produto termine em $a$ (a pronúncia é [bEJ్̃’grb], um dissílabo oxítono (diferente de "Jóca" e "Lúma", p. ex.); (b) apresenta onset complexo, o que nunca ocorre nos hipocorísticos; (c) não respeita as fronteiras das categorias de análise fonológica, nesse caso, a sílaba, pois <bel> não é sílaba em Belo, o que faz com que a lateral passe à posição de coda e se vocalize no ship. Um aspecto crucial afasta os dados em (09) de hipocorísticos de nomes compostos: nem sempre as bases apresentam a mesma quantidade de sílabas nos produtos (algumas fazem uso de uma e outras, de duas), como em (09b) e (09c), gerando formas trissilábicas, o que jamais acontece na hipocorização, que constitui processo de formação de palavra mínima (ARAÚJO, 1990). Assim, os dados em (09) apontam para outro processo não

10 Esse fato se deve, possivelmente, a um processo de lexicalização que pode ter ocorrido com a sílaba <zé>, pois, como se sabe, é bastante comum o nome José ser reduzido a Zé. 
- | O fenômeno da shippagem na nomeação de casais: um novo emprego do cruzamento vocabular

concatenativo de formação de palavras: a siglagem. Discutiremos essa questão com mais vagar na próxima seção. Antes, voltemos aos dados de shippagem a que tivemos acesso.

A terceira possibilidade estrutural une o início de um prenome com o meio de outro, tendo sido encontrado em apenas dois dados do corpus. Essas ocorrências, listadas a seguir, parecem ser intencionalmente motivadas já que as palavras finais correspondem a homônimos: "frito", "que se frigiu ou estar em situação embaraçosa, sem desculpas para uma falta, sem dinheiro, sem escapatória", e "viada" ( $\sim$ veada), "designação pejorativa, preconceituosa e depreciativa para se referir a homossexuais".

$$
\begin{aligned}
& \text { Frito }(<\underline{\text { Franciele }}+\text { Vitor }) \\
& \text { Viada }(<\underline{\text { Vivi }}+\text { Radamés })
\end{aligned}
$$

A quarta possibilidade de formação só ocorreu em um caso, que mescla o fim da primeira base com o início da segunda. Assim como em (10), esse caso isolado também parece ter sido formado com a intenção de fazer analogia com outra palavra de uso comum na língua: "pau" - "vara, ripa, viga; [chulismo] pênis". Nesses casos, está em jogo a função discursiva de avaliação, nos termos de Basilio (1987), uma vez que a intenção vai além da simples nomeação do par: contém claro propósito de denegrir o casal, o que se evidencia com a utilização de nomes comuns característicos de uma linguagem de baixo calão.

(11) $\quad$ Nopau $(<$ Breno $+\underline{\text { Paula })}$

A quinta e última possibilidade estrutural também ocorreu em um só caso, unindo, integralmente, a primeira MWd com as duas extremidades (esquerda e direita) da segunda. Entendemos que a excentricidade desse caso raro pode ser justificada pelo fato de as bases serem antropônimos mais comuns na língua inglesa, visto que ambos os nomes são referentes a personagens da série Supergirl. Novamente aqui predomina a função expressiva de avaliação. Nesse caso, no entanto, cria-se uma forma que evoca algo positivo e com conteúdo nitidamente afetivo: um doce, caramelo.

$$
\text { Karamel }(<\underline{\text { Kara }}+\underline{\text { Mon-el }})
$$

Apresentadas as cinco possibilidade estruturais, discorreremos, a seguir, sobre as duas mais recorrentes, consideradas, aqui, os efetivos padrões estruturais da shippagem em português. Começando pelos casos envolvendo a margem esquerda das formas de base, ressaltamos que em nenhum dos dados as bases compartilham material fonológico. Identificamos algumas situações em que as palavras-matrizes até apresentam semelhanças, mas essa similaridade fônica não foi aproveitada para a produção do ship. Por exemplo, "LuAr" (< Lua + A 
sílaba de rima ramificada - núcleo + coda - em Arthur). No entanto, pela grafia, é notório o aproveitamento da primeira sílaba de Lua, o que caracteriza uma correspondência de um-para-um (e não a existência de ambimorfemia).

Outro caso interessante é o de "TayTay" (<Taylor + Taylor), ship do ator Taylor Lautner e da cantora Taylor Swift. Os prenomes são idênticos e, portanto, todos os segmentos das bases podem ser considerados semelhantes, mas, ao selecionar a primeira sílaba de cada base, o shipper optou pelo aproveitamento de ambas as bordas esquerdas, criando uma espécie de forma reduplicada para ressaltar bem a união dos prenomes da nomeação amorosa em questão.

Desse modo, todos os 28 dados que se servem da borda esquerda dos antropônimos são classificados como combinação truncada e formalmente se assemelham a hipocorísticos de nomes compostos (com todas as ressalvas já levantadas). Entre ships e hipocorísticos, outra particularidade vale ser ressaltada: a mudança da estrutura silábica

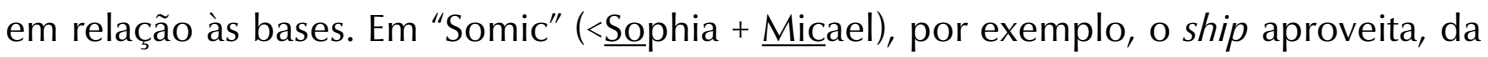
base Micael, a primeira sílaba $(/ \mathrm{mi} /)$ e o onset da segunda $(/ \mathrm{k} /)$, o que mostra que o processo pode operar na ressilabificação de segmentos, fato simplesmente inexistente na hipocorização de nomes compostos (cf. LIMA, 2008). Outro exemplo semelhante é "MerDer" ( $<$ Meredith + Derek), em que o tepe $/ \mathrm{r} /$, onset da segunda sílaba de ambas as bases, passa a $[\gamma]$ e $[\mathrm{x}]$, fricativa velar sonora e surda, respectivamente, ao assumir a posição de coda interna e externa, nesta ordem (pelo menos na fala carioca). Cumpre destacar que essa mudança estrutural também não costuma ocorrer em dados de CV em português (cf., p. ex., ANDRADE, 2008), embora seja bastante comum em outras línguas, como o inglês, conforme relatado em Lehrer (2007), e em francês (cf. RENNER; MANIEZ; ARNAUD, 2012). Por outro lado, mudança estrutural semelhante é observada em "BelGra" (<Belo +

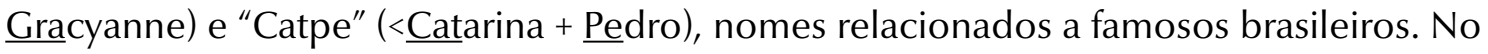
nosso entendimento, esses ships remetem ao processo de siglagem, como abordaremos adiante.

Os ships formados por margens diferentes das formas de base, como destacamos, são os que perfazem a maioria dos dados e, entre eles, a combinação truncada também prevalece sobre a interposição lexical (36\% contra 64\%). Com relação ao ponto de quebra, observamos que o corte nas bases é feito no nível intersilábico. Como exemplo, podemos

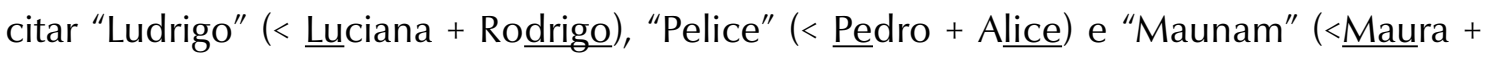
lonam), cujo material aproveitado no produto final é a borda esquerda de uma base e a direita de outra, considerando os aspectos discutidos mais acima, em relação à ordem das matrizes no interior dos ships. Um aspecto que merece destaque é o fato de, nos três casos, haver aproveitamento de sílabas, na íntegra. 
- | O fenômeno da shippagem na nomeação de casais: um novo emprego do cruzamento vocabular

Há, no entanto, outros dados igualmente formados por margens diferentes das formas de base e por combinação truncada cujo corte é feito no nível intrassilábico, uma vez que o material aproveitado corresponde a porções menores que a sílaba - é o caso de "Mafeu" (< Mafalda + Romeu), "Spoby" (< Spencer + Toby) e "Tatelson" ( $<$ Tatiana + Kelson). No primeiro exemplo, o corte é feito a partir da segunda sílaba de Mafalda, aproveitando, desta, apenas seu onset, $(/ \mathfrak{f} /)$, posteriormente ligado à rima da segunda sílaba de Romeu (/eひ్/). De igual modo, em "Spoby", o corte conecta o onset complexo (em inglês, /sp/) da primeira sílaba de Spencer, (/sp/), com o núcleo da primeira sílaba de Toby, (/o/). Em "Tatelson", novamente o onset de sua segunda sílaba de Tatiana, $(/ \mathrm{t} / \mathrm{)}$, é ligado à rima da primeira sílaba de Kelson $(/ \varepsilon \mho /$ /). Nos três casos, a quebra foi feita no interior de uma sílaba.

Observamos, assim, que os dados formados por margens diferentes das bases são heterogêneos quanto ao ponto de quebra, uma vez que, em alguns deles, o corte mantém as sílabas completas e, em outros, é interno às mesmas - o que denominamos de nível intersilábico e intrassilábico, respectivamente. Nossa hipótese para explicar a motivação de um ou outro é a questão do rastreamento das matrizes lexicais, a partir do aproveitamento do maior número de segmentos e das estruturas métrica e prosódica das bases. Outro ponto igualmente importante é o efeito fonológico da criação, ao evitar, por exemplo, que (a) uma matriz seja representada por uma sequência parecida com um afixo ou uma palavra e (b) o resultado soe estranho (a menos que isso seja intencional). Em "Pelice" ( $<$ Pedro + Alice) , se a quebra fosse feita no nível intrassilábico, o produto final (Pedrice) remeteria mais diretamente a Pedro, mas a base Alice seria de mais difícil reconhecimento, por conta da terminação ice, equivalente, em forma, ao sufixo formador de nomes abstratos (cf. chatice, burrice). Do mesmo modo, se o corte do ship "Mafeu" (<Mafalda + Romeu) fosse intersilábico, o resultado (Mameu ou Mafalmeu), além de apresentar sonoridade incomum, seria opaco quanto à identificação da base Romeu.

Concluindo, não identificamos nenhum ship monossilábico ou formado pela substituição sublexical. Observamos a combinação truncada como o tipo de cruzamento vocabular mais recorrente na shippagem, correspondendo a praticamente $70 \%$ dos 212 dados. Segue uma tabela que distribui os dados entre as possibilidades estruturais de ships e os tipos de cruzamento vocabular identificados. 
Tabela 1. Possibilidade estruturais de ships

\begin{tabular}{|l|c|c|c|c|c|c|}
\hline \multicolumn{2}{|c|}{ Análise estrutural dos ships } & \multicolumn{2}{c|}{ Interposição lexical } & \multicolumn{2}{c|}{ Combinação truncada } \\
\hline & UNID & $\%$ & UNID & $\%$ & UNID & $\%$ \\
\hline Início + fim & 180 & 85 & 65 & 31 & 115 & 54 \\
\hline Início + início & 28 & 13 & 0 & 0 & 28 & 13 \\
\hline Início + meio & 2 & 1 & 0 & 0 & 2 & 1 \\
\hline Fim + início & 1 & 0,5 & 0 & 0 & 1 & 0,5 \\
\hline Início + extrem. & 1 & 0,5 & 0 & 0 & 1 & 0,5 \\
\hline TOTAL & 212 & 100 & 65 & 31 & 147 & 69 \\
\hline
\end{tabular}

Fonte: Elaboração própria

Ainda que menos avaliativo do que os casos mais clássicos de interposição lexical, como "Boçalnaro", “Bozonero", "Coronaro” (cf. GONÇALVES, 2020), o significado veiculado pelos ships é também atitudinal, nos termos de Gonçalves (2016), posto que motivado por uma intenção específica do falante (o desejo de que o casal dê certo). Ao apoiar um ship publicamente, muitas evidências são reveladas sobre o falante (o internauta, nesse caso). Por exemplo, pelo simples fato de postar a hashtag\#Paugner em uma rede social, os leitores saberão que o autor da postagem é expectador do reality show Big Brother Brasil 18 e claramente torce pelo romance entre Paula e Wagner; logo, não deve apoiar o namoro da participante com nenhum outro jogador, e provavelmente torce para os dois terem bom desempenho no programa (caso contrário não daria "ibope" para o mesmo). Sendo assim, mais uma vez, constata-se que o antropônimo não se apresenta como "marca sem significado" ou "mero rótulo" (cf. SOLEDADE, 2019), revelando forte valor discursivo socialmente demarcado. Teria também função indexical, nos termos de Gonçalves (2016), uma vez que, pela shippagem, seriam reconhecidos traços sociolinguísticos do falante: geralmente jovens, a maioria adolescentes do sexo feminino.

\section{Paralelo entre cruzamento vocabular de bases antroponímicas e siglagem}

Examinados a estrutura dos dados e seus principais padrões de formação, investigamos agora outro processo morfológico que se aproxima da shippagem: a siglagem, em especial os casos de acronímia (cf. ABREU, 2004). Observamos que os 
- | O fenômeno da shippagem na nomeação de casais: um novo emprego do cruzamento vocabular

dados em questão, sobretudo os formados pelo aproveitamento da margem esquerda das formas de base, mostram-se semelhantes às siglas, palavras também formadas pelas iniciais de suas bases.

O paralelo entre a siglagem e o cruzamento vocabular não é inédito, pois foi apresentado no trabalho de Gonçalves (2004), ao juntar ambos os mecanismos de ampliação lexical no mesmo grupo, o de processos de fusão. Nesse sentido, definimos a siglagem para, depois, verificar algumas divergências e convergências entre siglagem e $\mathrm{CV}$, a fim de investigar se alguns ships podem ser considerados siglas.

Segundo Gonçalves (2019a, p. 255), uma sigla é uma "combinação das iniciais de um nome composto ou de uma expressão". Pode ser de dois tipos: (i) alfabetismo, em que os produtos são pronunciados letra por letra, como em uma soletração, a exemplo de UFMG, ou (ii) acrônimo, "siglas cuja combinação de letras possibilita pronunciar a nova forma como palavra comum na língua" (GONÇALVES, 2019a, p. 226), a exemplo de UERJ. Pela pronúncia dos dois tipos, selecionamos os acrônimos para comparação com os ships que se valem da borda esquerda das bases.

O primeiro ponto em comum é não concatenatividade, pois, assim como cruzamentos, siglas também não são formadas por encadeamento estrito de seus componentes. Além disso, siglagem e CV são processos de fusão, como afirma Gonçalves (2004). A fusão, inclusive, parece ser o fator que mais une os dois mecanismos. Em siglas como "Petrobras" ( $<$ Petróleo Brasileiro), é nítida a fusão pela qual as bases são processadas, incluindo o rompimento do constituinte sílaba (a sibilante /z/ passa a coda e se neutraliza). Esse exemplo também deixa claro que os CVs são mais parecidos com os acrônimos do que com os alfabetismos, uma vez que não necessariamente usam apenas a primeira letra de cada base da expressão; podem aproveitar mais segmentos. Em "Petrobras", são empregadas as duas primeiras sílabas da primeira palavra, ['petro], que se unem à primeira sílaba da segunda palavra, [bra], mais o onset da sílaba seguinte, /z/, o que torna neutralizável a pronúncia do produto, uma vez que, ao passar para a coda, pode ser realizado alveolar, [s] ou alveopalatal, [S], a depender do dialeto. Esse caso se aproxima de "BelGra" (< $\underline{\text { Belo }}+$ Gracyanne), por exemplo, que aproveita a primeira sílaba de Belo e o onset da segunda, formando uma palavra com ditongo na primeira sílaba e onset complexo na segunda. Esses fatos afastam os ships da classe dos hipocorísticos de nomes compostos, que, como vimos, são basicamente CV.CV e nunca operam no nível intrassilábico.

Outra semelhança entre os processos de shippagem e siglagem (acronímia) é que ambos possuem função lexical: como o CV, a siglagem também forma novas palavras por 
meio de bases já existentes na língua. Além disso, alguns ships formados pelas iniciais das bases são grafados com letras maiúsculas no interior da palavra, delimitando onde começa a segunda base - cf. "BelGra" (< $\underline{\text { Belo }}+$ Gracyanne) -, assim como ocorre com algumas siglas -"MinC" ( $<$ Ministério da Cultura). A quantidade de bases, por sua vez, é um critério que distancia os processos: enquanto dados de CV possuem invariavelmente duas bases, siglas apresentam no mínimo duas bases.

A relação do produto final com as bases é uma convergência entre os processos, na medida em que consideramos a autonomia dos produtos. O falante pode tomar um acrônimo como palavra primitiva, ou seja, siglas apresentam a possibilidade de criar derivados - cf. "petista" (< PT) e "aidético" (< AIDS). Ainda que não seja muito recorrente, verificamos uso parecido com "shirlipeiro"11, derivado em -eiro do "Shirlipe" $(<$ Shirlei + Felipe).

Comparando pelo critério semântico, há diferenças entre ships e acrônimos. Nos ships, o significado total é a soma dos significados de cada base, isoladamente, de modo que o falante, imerso na esfera social em que circulam essas formações, capta as bases e percebe o desejo do shipper de que dois personagens ou duas pessoas fiquem juntos (formem um par). Por exemplo, o ship "ToCar" pode ser opaco para muitos falantes, mas para os telespectadores da novela Rebelde, é de fácil acesso, já que mescla os nomes de um dos principais casais: Tomás e Carla.

Nas siglas, por sua vez, embora o significado total também seja resultante da combinação dos significados de cada base, o produto é mais distante de suas matrizes, o que se dá pela possibilidade de o falante não conseguir identificar as bases, como ocorre em "CEP" (< Código de Endereçamento Postal) e "BRT" (<Bus Rapid Transit, "Transporte Rápido por Ônibus"). Por exemplo, o fato de o falante conhecer o BRT não é garantia de que reconheça as bases da sigla, uma vez que são oriundas do inglês. Sobre isso, Gonçalves (2019, p. 226) afirma que

[...] o distanciamento das formas de base advém da pequena relação de identidade entre a sigla e a expressão, uma vez que apenas a sequência inicial é copiada. Em decorrência, é grande a probabilidade de o acrônimo suplantar de vez o sintagma-base, a exemplo do que vem ocorrendo com CPF (abreviação de 'cadastro de pessoas físicas'), que já não mantém qualquer relação de correspondência com a expressão que lhe deu origem.

11 Dado disponível em: https://glo.bo/3yLhxSJ.Acesso em: 10 out. 2016. 
- | O fenômeno da shippagem na nomeação de casais: um novo emprego do cruzamento vocabular

Como já afirmamos, há ships que aproveitam apenas as iniciais das bases, como em "JeLu" (< ¿éssica + Lucas); mas também há dados que aproveitam o início de uma base e o fim de outra, como "Artulia" (<사tur + Julia), além de outras possibilidades menos recorrentes. Nas siglas, ao contrário, independentemente de serem alfabetismos ou acrônimos, necessariamente aproveitam-se dos segmentos iniciais das bases, como em "Detran" ( $<$ Departamento de Trânsito) e "Secom" ( $<$ Secretaria do Comércio). Fica claro, então, que a maior diferença entre os processos é o fato de a siglagem formar palavras, necessariamente, por meio das iniciais de suas bases - tanto é que, em inglês, o termo utilizado é initialism ${ }^{12}$ (inicialismo).

Levando em conta os critérios apresentados - como resume o quadro a seguir - concluímos que os ships, principalmente os que preservam a borda esquerda das matrizes lexicais, têm características tanto de cruzamento vocabular como de siglas. Em um continuum entre os processos, provavelmente ficariam entre o CV e a siglagem. No quadro a seguir, apresentamos as principais semelhanças e diferenças entre os dois processos:

Quadro 1. Siglagem vs. cruzamento vocabular

\begin{tabular}{|c|l|l|l|}
\hline \multicolumn{1}{|c|}{ Critério } & \multicolumn{1}{|c|}{ Siglagem } & \multicolumn{1}{c|}{ CV (ship) } \\
\hline 1 & Formação & $\begin{array}{l}\text { Processo não concatenativo/ } \\
\text { fusão }\end{array}$ & $\begin{array}{l}\text { Processo não concatenativo/ } \\
\text { fusão }\end{array}$ \\
\hline 2 & Função & Função lexical & Função lexical \\
\hline 3 & $\begin{array}{l}\text { Quantidade mínima } \\
\text { de bases }\end{array}$ & Duas bases & Duas bases \\
\hline 4 & $\begin{array}{l}\text { Quantidade máxima } \\
\text { de bases }\end{array}$ & Permite mais de duas bases & Duas bases \\
\hline 5 & $\begin{array}{l}\text { Autonomia das } \\
\text { bases }\end{array}$ & Produto final pode ser derivado & Produto final pode ser derivado \\
\hline 6 & Semântico & $\begin{array}{l}\text { Significado das bases distante } \\
\text { do significado da nova palavra } \\
\text { (menos transparência) }\end{array}$ & $\begin{array}{l}\text { Significado das bases próximo } \\
\text { do significado da nova palavra } \\
\text { (mais transparência) }\end{array}$ \\
\hline 7 & Padrão estrutural & Permite 'início + início' & Permite pelo menos dois padrões \\
\hline
\end{tabular}

\section{Palavras finais}

Neste artigo, procuramos descrever as principais características de um fenômeno que se tornou febre entre os adolescentes, sobretudo os mais antenados com as mídias

12 O termo initialism, como tradução para siglagem, é encontrado no dicionário on-line de inglês Oxford. Disponível em: https://en.oxforddictionaries.com/spelling/initialisms. Acesso em: 10 set. 2018. 
sociais e as diversas séries de TV que vêm se popularizando, por exemplo, na Netflix: a shippagem. Ao mostrarmos que a formação de ships constitui prática bastante recente na criação de nomes, observamos que a criação lexical revela forte desejo de batizar uma relação afetiva por meio da combinação de dois antropônimos, a exemplo de "BelGra", junção do nome artístico de um cantor romântico, Belo, com o prenome de uma conhecida fisiculturista, Gracyanne Barbosa.

Esperamos, no texto, ter alcançado as seguintes metas: (a) mostrar que a shippagem é um fenômeno a serviço da Onomástica, uma vez que parte de nomes de pessoas com vistas a formar um nome composto, ainda que este não seja real; e (b) ao analisar os padrões mais frequentemente empregados na construção de ships, comprovar que o cruzamento vocabular, em sua diferente tipologia (interposição, combinação truncada, substituição sublexical) responde pela maioria das formações, ainda que interaja, em menor proporção, com outros processos não concatenativos, principalmente a siglagem e hipocorização, o que evidencia não serem rígidas as fronteiras dos processos de formação de palavras, mesmo os não concatenativos. Esperamos que, por sua natureza seminal, o trabalho sirva para estimular novos estudos nessa área tão recente e ainda tão pouco descrita.

\section{REFERÊNCIAS}

ABREU, K. N. M. de. Um caso de morfologia improdutiva no português do Brasil: a formação de siglas e de acrônimos. 2004. Dissertação (Mestrado em Linguística) Faculdade de Letras, Universidade Federal do Rio de Janeiro, Rio de Janeiro, 2004.

ALGEO, J. Blends, a structure and sistematic view. American Speech, v. 52, p. 47-64, 1977.

ALVES, I. M. Neologismo: criação lexical. São Paulo: Ática, 1989.

ARAÚJO, G. A. Morfologia não-concatenativa em português: os portmanteaux. Caderno de Estudos linguísticos, Campinas, v. 39, p. 5-21, 1990.

ASSUNÇÃO, F. P.; GONÇALVES, C. A. V. Cruzamentos vocabulares em nível discursivo/ textual: efeitos expressivos e padrões estruturais na coluna de Agamenon Mendes Pedreira. Signum, Estudos de Linguagem, v. 11, p. 111-130, 2008. 
- | O fenômeno da shippagem na nomeação de casais: um novo emprego do cruzamento vocabular

ANDRADE, K. E. Uma análise otimalista unificada para mesclas lexicais do Português do Brasil. 2008. Dissertação (Mestrado em Letras Vernáculas) - Faculdade de Letras, Universidade Federal do Rio de Janeiro, Rio de Janeiro, 2008.

ANDRADE, K. E. Proposta de continuum composição-derivação para o português do Brasil. 2013. Tese (Doutorado em Letras Vernáculas) - Faculdade de Letras, Universidade Federal do Rio de Janeiro, Rio de Janeiro, 2013.

BASILIO, M. Teoria Lexical. São Paulo: Ática, 1987.

BASILIO, M. M. de P. A fusão vocabular como processo de formação de palavras. Anais IV Congresso Internacional da ABRALIN, Salvador: UFBA, p. 545-555, 2005.

BECKMAN, J. N. Positional faithfulness. 1998. Dissertação (Doutorado em Filosofia) Graduate School of theUniversity of Massachussetts, Amherst, 1998.

BENFICA da SILVA, V. O cruzamento vocabular formado por antropônimos: análise morfológica e fonológica. Dissertação (Mestrado em Letras) - Faculdade de Letras, Universidade Federal do Rio de Janeiro, Rio de Janeiro, 2019.

CARVALHO, J. J. de. A formação de palavras na língua portuguesa: um estudo da fusão vocabular na obra de Mia Couto. 2008. Dissertação (Mestrado em Letras) - Pontifícia Universidade Católica, Rio de Janeiro, 2008.

DOW, L. A corpus study of phonological factors in novel English blends. Lexis, v. 45, n. 3, p. 111-123, 2018.

GIROLAMO, C. The Fandom PairingName Blends and the Phonology-Orthography Interface. Names, v. 60, n. 4, p. 231-243, 2019. DOI: 10.1179/0027773812Z.00000000034.

GONÇALVES, C. A. V. Uma análise compreensiva do cruzamento lexical em português. Campinas: Pontes (no prelo)

GONÇALVES, C. A. V. Uma análise construcional das (de)formações lexicais com os nomes do atual chefe do executivo. Gragoatá (UFF), v. 25, n. 52, p. 648-687, 2020.

GONÇALVES, C. A. V. Morfologia. São Paulo: Parábola, 2019a. 
GONÇALVES, C. A. V. A crença nas palavras: (des)construções lexicais em antropônimos de líderes religiosos. Estudos Linguísticos (São Paulo. 1978), v. 48, p. 899-918, 2019b.

GONÇALVES, C. A. V. Atuais tendências em formação de palavras. São Paulo: Contexto, 2016.

GONÇALVES, C. A. V. A ambimorfemia de cruzamentos vocabulares em português: uma abordagem por ranking de restrições. Revista da ABRALIN, v. 5, p. 169-184, 2006.

GONÇALVES, C. A. V. Processos morfológicos não-concatenativos: formato prosódico e latitude funcional. Alfa (ILCSE/UNESP), Araraquara, v. 48, n. 2, p. 30-66, 2004.

GONÇALVES, C. A. V. Blends lexicais em português: não-concatenatividade e correspondência. Veredas (UFJF), Juiz de Fora, v. 14, n. 1, p. 16-35, 2003.

GONÇALVES, C. A. V.; CARVALHO, W.; ANDRADE, K. Splinters são cruzamentos de cruzamentos? Repensando o estatuto desse constituinte em português. Revista do GEL, São Paulo, v. 13, n. 1, p. 132-156, 2016.

GONÇALVES, C. A.; ANDRADE, K. E.; ALMEIDA, M. L. L. Se a macumba é para o bem, então é boacumba: análise morfoprosódica e semântico-cognitiva das substituições sublexicais em português. Revista Lingüística, Revista do Programa de Pós-Graduação em Linguística da Universidade Federal do Rio de Janeiro, v. 6, n.2, p. 47-62, dez. 2010.

GONÇALVES, C. A. V.; SALGADO, V. C. Sobre o efeito da restrição morfológica Morphdis nos cruzamentos vocabulares em português. In: IV Congresso Internacional da ABRALIN. Brasília. Anais do IV Congresso Internacional da ABRALIN. Brasília: UnB, v. 1. p. 195-202, 2006.

LEHRER, A. Blendalicious. In: MUNAT, J. (ed.). Lexical Creativity, Texts and Contexts, Amsterdam/Philadelphia: Benjamins, 2007. p. 115-133.

LIMA, B. C. A formação de 'Dedé' e 'Malu': uma análise otimalista de dois padrões de Hipocorização. 2008. Dissertação (Mestrado em Letras Vernáculas) - Faculdade de Letras, Universidade Federal do Rio de Janeiro, Rio de Janeiro, 2008. 
- | O fenômeno da shippagem na nomeação de casais: um novo emprego do cruzamento vocabular

MCCARTHY, J. A prosodic theory of nonconcatenative morphology. Linguisticlnquiry, v. 12, n. 3, p. 373-417, 1986.

PIÑEROS, C. E. The creation of portmanteaus in the extra grammatical morphology of spanish. Iowa: University of lowa, 2002.

RENNER, V.; MANIEZ, F.; ARNAUD, P. J .L. Cross-Disciplinary Perspectives on Lexical Blending. Berlin/Boston: De Gruyter, 2012.

RIO-TORTO, G. M. Blending, cruzamento ou fusão lexical em português: padrões estruturais e (dis)semelhanças com a composição. Filologia e lingüística portuguesa, São Paulo, v. 16, n. 1, p. 7-29, jan./jun. 2014.

LIEBER, R. English Word-Formation Processes. In: ŠTEKAUER, P.; LIEBER, Handbook of Word-Formation. Cambridge: Cambridge University Press, 2005. p. 429-448.

RONNEBERGER-SIBOLD, E. Tuning Morpho-Semantic Transparency by Shortening. In: LÜTSCHUZKY, H.; RAINER, F. (ed.). Proceedings of the 15th International Morphology Meeting. Amsterdam/Philadelphia: John Benjamins, 2013. p. 206-225.

SANDMANN, A. J. Morfologia geral. São Paulo: Contexto, 1989.

SANDMANN, A. J. Formação de palavras no português brasileiro contemporâneo. Curitiba: Scientia et Labor, 1985.

SÂNDALO, M. F. Morfologia. In: MUSSALIN, F.; BENTES, A. C. (ed.). Introdução à lingüística. São Paulo: Cortez, 2001.

SOLEDADE, J. Origens e estruturação histórica do léxico antroponímico do português brasileiro. Macabéa - Revista Eletrônica do Netlli, v. 8, n. 2, p. 411-452, jul./dez. 2019.

http://wp.clicrbs.com.br/holofote

http://www.garotasgeeks.com

https://aminoapps.com

https://capricho.abril.com.br/vida-real/nem-ai-13-casais-que-vamos-shippar-hojeamanha-e-sempre

https://tvefamosos.uol.com.br/blog/mauriciostycer 
https://twitter.com/fanfics

https://bit.ly/3H6U2GH

https://bit.ly/3stXbft

https://www.significados.com.br/shippar

http://sherlockbrasil.blogspot.com.br

COMO CITAR ESTE ARTIGO: GONÇALVES, Carlos Alexandre; SILVA, Vitória Benfica da. O fenômeno da shippagem na nomeação de casais: um novo emprego do cruzamento vocabular. Revista do GEL, v. 18, n. 3, p. 335-365, 2021.

Disponível em: https://revistadogel.gel.org.br/

Submetido em: 12/01/2021 | Aceito em: 04/02/2021. 